\title{
'Ca. Liberibacter asiaticus' Carries an Excision Plasmid Prophage and a Chromosomally Integrated Prophage That Becomes Lytic in Plant Infections
}

\author{
Shujian Zhang, ${ }^{1}$ Zomary Flores-Cruz, ${ }^{1}$ Lijuan Zhou, ${ }^{2}$ Byung-Ho Kang, ${ }^{3}$ Laura A. Fleites, ${ }^{1}$ Mark D. Gooch, ${ }^{4}$ \\ Nelson A. Wulff, ${ }^{5}$ Michael J. Davis, ${ }^{6}$ Yong-Ping Duan, ${ }^{7}$ and Dean W. Gabriel ${ }^{1}$ \\ ${ }^{1}$ Plant Pathology Dept., University of Florida, Gainesville, FL 32611, U.S.A.; ${ }^{2}$ Indian River Research and Education Center, \\ University of Florida, Ft. Pierce, FL 34945, U.S.A.; ${ }^{3}$ Microbiology and Cell Science Dept., University of Florida, Gainesville, \\ FL 32611, U.S.A.; ${ }^{4}$ Division of Plant Industry, Florida Department of Agriculture and Consumer Services, Gainesville, \\ FL 32608, U.S.A.; ${ }^{5}$ Departamento Científico, Fundecitrus, Araraquara, SP 14807-040, Brazil; ${ }^{6}$ Citrus Research and Education \\ Center, University of Florida, Lake Alfred, FL 33850, U.S.A.; ${ }^{7}$ Horticultural Research Laboratory, USDA-ARS, Fort Pierce, \\ FL 34945, U.S.A.
}

Submitted 3 November 2010. Accepted 14 December 2010.

Huanglongbing (HLB), also known as citrus greening, is a lethal disease of citrus caused by several species of ' $\mathrm{Candi}$ datus Liberibacter', a psyllid-transmitted, phloem-limited, alpha proteobacteria. 'Ca. Liberibacter asiaticus' is widespread in Florida citrus. The recently published ' $\mathrm{C}$ a. L. asiaticus' psy62 genome, derived from a psyllid, revealed a prophage-like region of DNA in the genome, but phage have not been associated with ' $\mathrm{Ca}$. $\mathrm{L}$. asiaticus' to date. In the present study, shotgun sequencing and a fosmid DNA library of curated ' $C a$. L. asiaticus' UF506, originally derived from citrus symptomatic for HLB, revealed two largely homologous, circular phage genomes, SC1 and SC2. SC2 encoded putative adhesin and peroxidase genes that had not previously been identified in ' $\mathrm{Ca}$. L. asiaticus' and which may be involved in lysogenic conversion. SC2 also appeared to lack lytic cycle genes and replicated as a prophage excision plasmid, in addition to being found integrated in tandem with SC1 in the UF506 chromosome. By contrast, SC1 carried suspected lytic cycle genes and was found in nonintegrated, lytic cycle forms only in planta. Phage particles associated with ' $\mathrm{Ca}$. L. asiaticus' were found in the phloem of infected periwinkles by transmission electron microscopy. In psyllids, both SC1 and SC2 were found only as prophage.

Citrus greening, also known as Huanglongbing (HLB), is arguably the most damaging disease of citrus world wide, resulting in substantial fruit production losses and greatly shortened lifespan of infected trees (Bové 2006; Brlansky and

Current address for Zomary Flores-Cruz: Microbiology Dept., University of Georgia, Athens, GA 30602, U.S.A.

Corresponding author: D. W. Gabriel; E-mail: dgabr@ufl.edu; Telephone: +1.352 .392 .7329 ; Fax: +1.352 .392 .6532 .

Two circular phage genomes from $\mathrm{Ca}$. L. asiaticus UF506 have been deposited in GenBank under accession numbers HQ377372 (SC1) and HQ377373 (SC2), and the UF506 chromosomal fragment carrying both integrated phage genomes has been deposited as accession number HQ377374.

* The $\boldsymbol{e}$-Xtra logo stands for "electronic extra" and indicates that five supplementary tables and four supplementary figures are published online.
Rogers 2007; Gottwald et al. 2007). There are three recognized species of the insect-vectored, phloem-limited, and fastidious causal agent, the $\alpha$-proteobacteria 'Candidatus Liberibacter asiaticus', 'Ca. L. africanus', and ' $C a$. L. americanus' (Jagoueix et al. 1997). These bacteria replicate at such low titers in citrus that detection often depends upon use of nested polymerase chain reaction (PCR) (PCR amplification of a PCR product). In addition, HLB has a long latency period; combined with low titer and initially ambiguous symptoms of blotchy mottling, the combination makes detection at early stages of a pandemic practically impossible. The Asian citrus psyllid vector of HLB, Diaphorina citri, was discovered in Florida in 1998 (Halbert and Manjunath 2004) and, over the next two years, had spread to all major citrus-growing regions of the state. HLB was then discovered in Florida in 2005 (Sutton et al. 2005) and was confirmed to have spread to all citrus growing counties in the state by 2007 . The insect vector was found in Texas in 2004 (Da Graca and Korsten 2004) and California in 2008 (Citrus Research Board 2008).

There are some interesting pathogenic, host range, and physiological variants found among Liberibacters. ' $\mathrm{Ca}$. L. asiaticus' is distributed worldwide on citrus and is heat tolerant; ' $C a$. L. africanus' has been found only in Africa and Yemen on citrus and produces no symptoms above $30^{\circ} \mathrm{C}$. ' $\mathrm{Ca}$. L. americanus' is found only in Brazil, where both ' $\mathrm{Ca}$. L. americanus' and ' $\mathrm{Ca}$. L. asiaticus' are associated with HLB (Coletta-Filho et al. 2005). ' $C a$. L. americanus' was the predominant species when HLB was first found in 2004 (Teixeira et al. 2005), but after 2006, there was a disproportionate increase in the occurrence of ' $\mathrm{Ca}$. L. asiaticus', with ' $\mathrm{Ca}$. L. americanus' becoming more difficult to find (Lopes et al. 2009a). ' $\mathrm{Ca}$. L. americanus', besides being found only in Brazil, is also heat sensitive (Lopes et al. 2009b). 'Ca. L. asiaticus' may be experimentally transmitted by dodder to citrus and, surprisingly, also to several Solanaceous plants, including tomato and tobacco (Duan et al. 2008; Garnier and Bové 1983; Halbert and Manjunath 2004). In addition to the Liberibacter species causing HLB on citrus, a new species, ' $\mathrm{Ca}$. L. solanacearum', is the causal agent of zebra chip, an emerging disease of potatoes in the U.S. and tomatoes in New Zealand (Liefting et al. 2008). Another new species, ' $C a$. L. psyllaurous', was found to infect tomato and potato and is vectored by the psyllid Bactericera cockerelli (Hansen et al. 2008). Variation in citrus host range, titer, and 
disease severity among ' $\mathrm{Ca}$. L. asiaticus' strains has been reported (Tsai et al. 2008), and such variation has been associated with prophage gene variation (Tomimura et al. 2009).

Bacteriophages (phages) are viruses that infect bacteria. Lytic phages infect the bacterial host, replicate, and then lyse the host cell to release progeny. Temperate phages, although capable of lytic cycle infections, are able to repress transcription of their structural genes and suppress the lytic cycle, entering a stable, lysogenic stage, either integrated into the host chromosome as a prophage or, more rarely, replicating as a plasmid prophage (Casjens 2003; Ptashne 2004). Interestingly, although lytic cycle genes are not expressed in prophages, nonlysis, nonstructural, and nonvirion assembly genes typically are expressed (Casjens 2003). If such expressed genes alter the physiology or pathogenicity of the host, the genes are considered to be lysogenic conversion genes (Boyd and Brussow 2002; Wagner and Waldor 2002). Such lysogenic conversion genes include virulence factors and pathogenicity islands and are thought to play an important role in the emergence of new pathogens and disease forms (Boyd et al. 2001; Wagner and Waldor 2002)

Liberibacter species have not been reported continuously cultured, and therefore, obtaining ' $\mathrm{Ca}$. L. asiaticus' DNA is extremely difficult. The ' $\mathrm{Ca}$. L. asiaticus' psy62 genome (Gen-

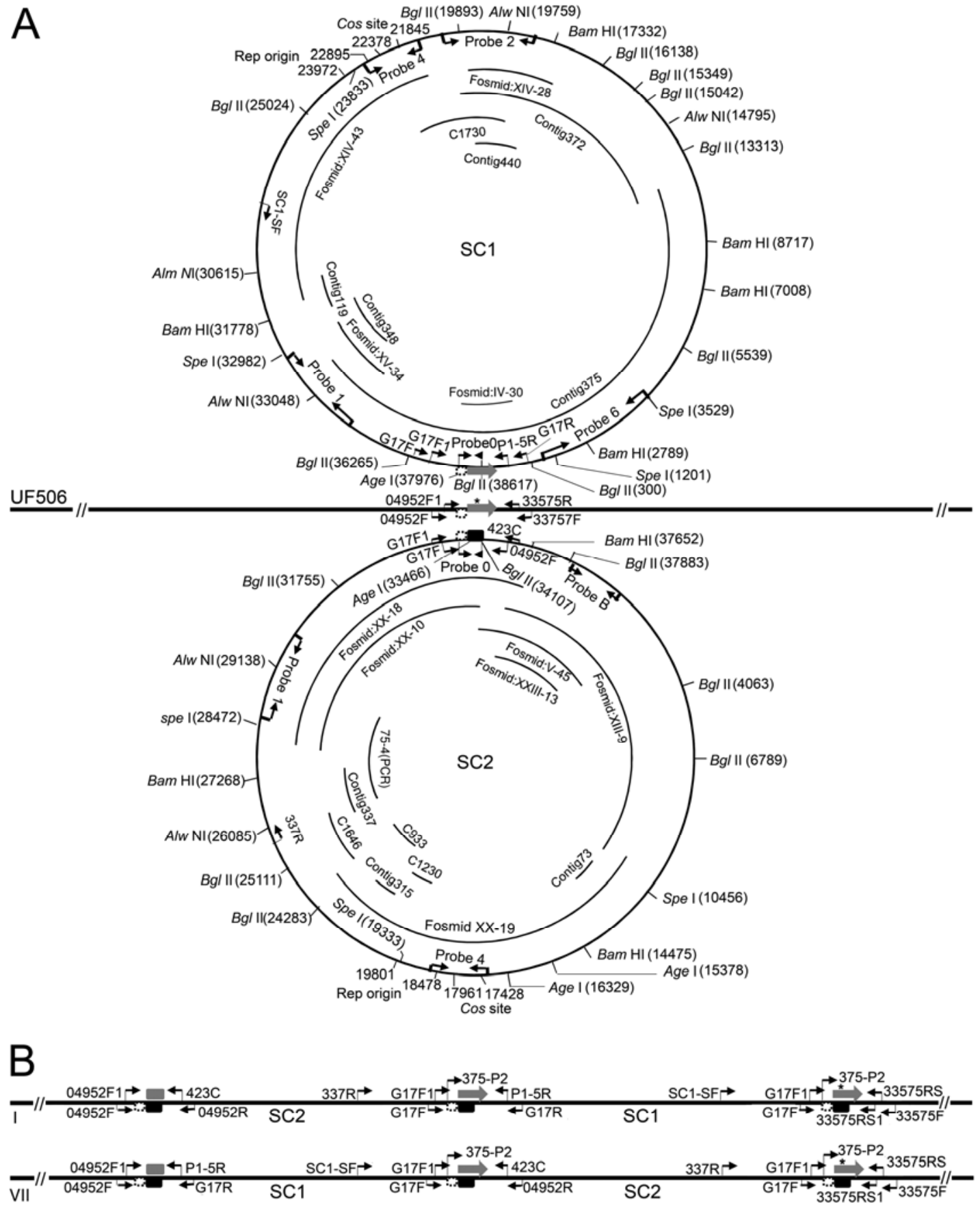

Fig. 1. Genome maps of SC1 and SC2. A, schematic map of SC1 and SC2 as found replicating in the UF506 genome. Restriction sites and the locations of probes for Southern blots are shown. B, Schematic map of SC1 and SC2 as found integrated in the UF506 genome. Primers used to determine phage integration sites and gene order are shown. Black and gray rectangles represent perfect, tandem, 1,111-bp repeats. Gray arrows represent perfect, tandem, 1,476-bp repeats, each of which starts with and incorporates the 1,111-bp repeat as indicated. Asterisks indicate the highly variable prophage integration junction region. Dotted boxes represent imperfect tandem repeats of approximately $3.3 \mathrm{~kb}$. 
Bank NC_012985.2) was obtained by multiple displacement amplification (MDA) of DNA obtained from a single infected psyllid (Duan et al. 2009). The psy62 genome revealed an $\alpha$ proteobacteria with a greatly reduced genome $(1.23 \mathrm{Mb})$, almost no potentially offensive pathogenicity factors, such as degradative enzymes or type III secretion system components, and what appeared to be very little defense against reactive oxygen species (ROS) (Duan et al. 2009). In the present study, MDA was used to obtain ' $C a$. L. asiaticus' DNA from infected citrus and periwinkle, and phage DNA, which included two previously unreported peroxidase genes, was highly overrepresented in both cases.

Here, we report two highly related, circular bacteriophage genomes associated with ' $\mathrm{Ca}$. L. asiaticus', named SC1 and $\mathrm{SC} 2$. Both were found integrated into the ' $\mathrm{Ca}$. L. asiaticus' UF506 genome as prophage. SC1 seemed to be a fully functional, temperate phage with a lytic cycle that appeared to be activated when its ' $\mathrm{Ca}$. L. asiaticus' host was infecting plants but not when infecting psyllids. SC2 appeared to be a degenerated form of SC1 that lacked lysis genes and carried several genes that could be important in lysogenic conversion, including the two peroxidases. SC2 was found replicating as an excision plasmid when its ' $\mathrm{Ca}$. L. asiaticus' host was infecting either plants or psyllids. The gene organization and location of the two prophages in the ' $\mathrm{Ca}$. L. asiaticus' genome and annotation of the phage genomes are discussed.

\section{RESULTS}

\section{Phage DNA was overrepresented}

in ' $\boldsymbol{C} \boldsymbol{a}$. L. asiaticus'-infected dodder.

From the UF506 dodder sample (passaged from field-infected citrus through dodder to periwinkle and then from infected periwinkle into clean dodder), a total of 14,000 shotgun library reads of $1.2-\mathrm{kb}$ average insert size were obtained and assembled into 1,127 contigs of size $>1 \mathrm{~kb}$. The largest 100 contigs, ranging in size from 1.2 to $17 \mathrm{~kb}$, were analyzed by comparisons against the GenBank nonredundant (nr) database, using BLAST and PFAM. After eliminating contigs with $>50 \%$ GC content (which appeared to represent plant nuclear DNA, chloroplast, mitochondrial, or bacterial DNA), the vast majority of open reading frames (ORF) from the remaining larger contigs appeared to be phage related, indicating a strong bias in the genomic library sample from dodder and, possibly, the existence of replicating phage particles associated with ' $\mathrm{Ca}$. L. asiaticus'. Primers amplifying approximately $1.4-\mathrm{kb}$ regions from four separate contigs were used to amplify the fragments from infected periwinkles. These fragments were cloned and were then sequenced to confirm the SeqWright shotgun assemblies in these regions. These same fragments were also used to probe the UF506 fosmid library blot.

\section{Two circular phage genomes readily assembled from fosmid DNA derived from ' $\mathrm{Ca}$. L. asiaticus'-infected dodder.}

Ten DNA clones from a fosmid library of ' $\mathrm{Ca}$. L. asiaticus' UF506 were sequenced by primer walking, and one PCR product was sequenced. These data were combined with the sequences from 12 contigs from shotgun sequencing to reveal two, highly related, circular contigs (Fig. 1A) of 40,048 and 38,997 bp, named SC1 and SC2 (GenBank accession numbers HQ377372 and HQ377373, respectively). Nearly all ORF predicted on these circles were either phage-related or "hypothetical unknown" sequences (Supplementary Tables S4 and S5), indicating circular phage genomes. In addition, extensive PCR analyses were performed using primers specific to both $\mathrm{SC} 1$ and SC2, such that the entire circular sequence of each pre- sumed phage was covered, followed by either restriction digestion analysis of the PCR products, sequencing, or both (data not shown).

\section{Southern blots revealed that both SC1 and SC2 were cut into full-length linear fragments at a presumed cos site, indicating both phages were packaged in periwinkle.}

In order to confirm the two highly related circular phage assemblies, extensive Southern blot and PCR analyses were performed using DNA extracted from infected periwinkle. Six pairs of primers from both phages were used to make the probes used in Southern blot analyses (Supplementary Table $\mathrm{S} 2$ ); the blots, with predicted sizes indicated when using different probes and different restriction endonucleases in various combinations, are shown in Supplementary Figure S1. All predicted fragments were confirmed present in the blots, which revealed the location of the phage cos sites of both phages (Supplementary Table S1). Based on subsequent analyses of $B a m \mathrm{HI}$ and $B g l \mathrm{II}$ restriction patterns predicted from the SC1 sequence when using probe 2 , the position of a predicted cos site on SC1 was mapped to an intergenic region between genes SC1_gp115 and SC1_gp120 (between positions 21,845 and 22,378) (Fig.1A). Similarly, probe 4 was used to determine a predicted $\cos$ region on SC2. Based on predicted BamHI, $B g l \mathrm{II}$, and SpeI restriction digest patterns from circular SC2 phage sequence data, the cos region was determined to lie between genes SC2_gp115 and SC2_gp120 on SC2 (positions $17,428$ to 17,962$)$ (Fig. 1A).

One of several fosmid clones that carried the uncut predicted cos site of SC1 was XIV-43; one of several fosmid clones that carried the uncut presumed cos site of SC2 was XX-19 (Fig. 1A). Nevertheless, the sole forms of both SC1 and SC2 revealed by Southern blots of DNA extracted from periwinkles were double-stranded linear DNAs cut at conserved, putative $\cos$ sites present on both genomes. Predicted fragments of SC1 and SC2 from the replicating circular forms were not detected in Southern blots. Since both phages were found to be processed at presumed cos sites and were abundantly represented in Southern blots, both phages were presumed to also be packaged.

\section{SC1 accumulated to higher levels than did SC2 in periwinkle and citrus, with lower levels of both found in psyllids.}

In attempts to compare the copy number of SC1 and SC2 in tissue samples taken from psyllids, citrus, and periwinkle, real time (rt)PCR was used. Since ' $\mathrm{Ca}$. L. asiaticus' was present in widely variable amounts in every sample taken from any source, each rtPCR run was normalized to 100 copies of gene prfA, a single-copy ' $\mathrm{Ca}$. L. asiaticus' gene. Primers were also designed (Supplementary Table S3) to amplify two genes unique to SC1 (SC1-gp110 and SC1_gp235) and two unique to SC2 (SC2_gp065 and SC2_gp240). Gene copy number was calculated relative to $p r f A$, and results of three samples each from psyllids, citrus, and periwinkle are presented in Supplementary Figure S3. In all three psyllid samples, the SC1- and SC2-specific genes were detected at the same approximate levels as prfA. Variability among the plant samples, particularly citrus, was striking. In citrus, all three samples showed higher levels of SC1 but only one of three samples showed significant amplification of either SC1- (15 to 25 times) or SC2-specific (three to five times) genes. SC1-specific genes in all periwinkle samples amplified to a copy level at least 20 times that observed for prfA, while SC2-specific genes amplified to a copy level ranging from approximately three to 20 times higher than prfA. Since no reverse-transcriptase step was performed, these levels of DNA amplification and variability indicated that 
phage DNA accumulation of both SC1 and SC2 occurred in some plant samples, including citrus, but more consistently in periwinkle.

\section{Phage particles associated with ' $\mathrm{Ca}$. L. asiaticus' UF506 were found in the phloem of infected periwinkles by transmission electron microscopy (TEM).}

In order to determine if phage particles could be observed in periwinkle, ' $C a$. L. asiaticus'-infected periwinkle samples were examined by electron microscopy. Ten ' $\mathrm{Ca}$. L. asiaticus'-infected and ten healthy periwinkle leaf samples were used in double-blind tests to confirm the presence of suspected phage particles associated with UF506 ' $\mathrm{Ca}$. L. asiaticus'. All samples were confirmed by conventional PCR to be either strongly 'Ca. L. asiaticus'-positive or ' $C a$. L. asiaticus'-negative, using primer set $\mathrm{K}$ (OI1 and OI2c) and $\mathrm{K}+(\mathrm{CG} 03 \mathrm{~F}$ and CG05R) as nested primers before conducting TEM analysis (data not shown). Phage particles were readily found in the phloem cells of nine out of the ten ' $\mathrm{Ca}$. L. asiaticus'-infected periwinkle samples (Fig. 2). Phage particles were not observed in any of the ten healthy periwinkle samples.

Based on the calculated sizes of 57 individual phages in photos similar to those in Figure 2, the average phage head size was estimated to be approximately $21.30 \mathrm{~nm}$. Based on orientation of phage heads and apparent attachment of 25 phages to ' $\mathrm{Ca}$. L. asiaticus' cells in photos similar to those in Figure 2B, the average neck length was approximately 5.03 $\mathrm{nm}$. Based on the relatively short neck length, the observed phage particles belong to family Podoviridae.

\section{SC1 and SC2 were found both separately and simultaneously integrated \\ in the UF506 chromosome in all hosts tested.}

In order to determine if one, both, or neither phage were integrated into the UF506 genome, PCR primers specific for both $\mathrm{SC} 1$ and $\mathrm{SC} 2$ and specific for the upstream and downstream ' $C a$. L. asiaticus' chromosomal regions predicted by the psy62 genome assembly to form junctions with a prophage sequence were designed (Fig. 3). Two nested UF506 chromosomal primer sets, $04952 \mathrm{~F}$ and $04952 \mathrm{~F} 1$ (unique chromosomal sites adjoining the predicted upstream side of the psy62 prophage region, using the gene order of the psy62 prophage region; GenBank accession NC_012985.2) and 33757RS, and $33575 \mathrm{~F}$ (unique chromosomal sites adjoining the predicted downstream side of the psy62 prophage region) were designed just outside of the anticipated prophage region. Unique chromosomal left-side and right-side primers were used in conjunction with various $\mathrm{SC} 1$ and $\mathrm{SC} 2$ primers to determine if one or both phages integrated in the UF506 genome. Primer sets G17F and G17F1 (found on both SC1 and SC2), SC1-SF, P15R, and G17R (unique to SC1), and 337R, 04952R, and 423C (unique to $\mathrm{SC2}$ ) were used together with the upstream and downstream chromosomal primer sets to determine that both SC1 and SC2 were found, sometimes separately and sometimes simultaneously, integrated into the UF506 genome as prophage. The different forms of integrated prophage and replicating circular phage found in periwinkle, citrus, and psyllids are shown in Figure 3, based on PCR evidence presented in the following section.

When both phages were simultaneously integrated as prophage, they presented primarily as form I (GenBank accession HQ377374), although form VII was also found (Fig. 3). Form I was demonstrated by amplification of PCR products using primer sets $\mathrm{E}$ (04952F and 04952R), G (337R and G17R), and I (SC1-SF and 33575RS), together with nested primer set E+ (04952F1 and 04952R), G+ (337R and P1-5R), and I+ (SC1$\mathrm{SF}$ and 33575RS1), respectively, in periwinkle, citrus, whole psyllid, and psyllid alimentary canals. Form VII was demonstrated by primers sets D (04952F and G17R), H (SC1-SF and 04952R), and $\mathrm{J}$ (337R and 33575RS), together with nested primer set D+ (04952F1 and P1-5R), H+ (SC1-SF and 423C), and $\mathrm{J}+(337 \mathrm{R}$ and $33575 \mathrm{RS} 1)$. While form $\mathrm{I}$ was prevalent in all ' $\mathrm{Ca}$. L. asiaticus' hosts tested, form VII was barely detected in infected periwinkles, citrus, and whole psyllids and not at all in psyllid alimentary canals, indicating that this form is present only in plants (presence in whole psyllids is presumably due to recent acquisition of ' $\mathrm{Ca}$. L. asiaticus' from plant tissue).

\section{SC1 and SC2 were both found simultaneously replicating in circular form in planta; only SC2 replicated in circular form in psyllid alimentary canals.}

Based on contig assembly from fosmids (discussed above), the circular replicating forms of SC1 (form V; GenBank accession HQ377372) and SC2 (form VI; GenBank accession HQ377373) were readily found in periwinkle. PCR products amplified using primer set B (G17F and 04952R) or nested primer set $\mathrm{B}+(\mathrm{G} 17 \mathrm{~F} 1$ and $423 \mathrm{C})$ revealed the presence of the circular replicating form of SC2 (form VI) in citrus and whole psyllids, in addition to confirming the presence of form VI in periwinkle. The presence of the circular replicating form $\mathrm{V}$ of $\mathrm{SC} 1$ in citrus and whole psyllids was deduced from the product formed by primer set A (G17F and G17R) that could be generated by either form I (integrated tandem prophage) or form $\mathrm{V}$ (replicating SC1) with a strong band from the first round of PCR, using DNA samples from citrus and whole psyllids, while the PCR products of primer set $\mathrm{C}(\mathrm{G} 17 \mathrm{~F}$ and $33575 \mathrm{~F})$ or primer set $\mathrm{C}$ and nested primer set $\mathrm{C}+(\mathrm{G} 17 \mathrm{~F} 1$ and 33575RS) indicated the presence of forms I, II, IV, and VII only in the second round of PCR (Supplementary Fig. S2). The absence of circular replicating form $\mathrm{V}$ of $\mathrm{SC} 1$ in psyllid alimentary canals was deduced from the fact that primer set $\mathrm{A}$ (G17F and G17R) followed by nested primer set A+ (G17F1 and P1-5R) gave only a barely detected band by nested PCR using DNA samples from psyllid alimentary canals (indicating
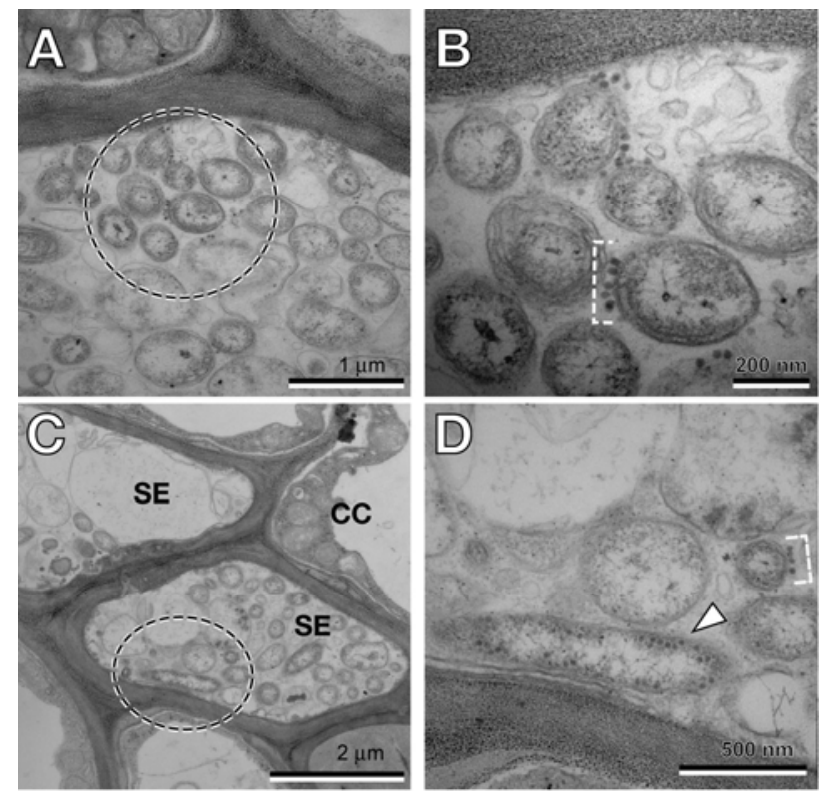

Fig. 2. Phage particles viewed by transmission electron microscopy in the phloem of 'Candidatus Liberibacter asiaticus'-infected periwinkles. A and C, 'Ca. L. asiaticus'-infected periwinkle phloem. B and D, Higher magnification image of the areas marked with dashed circles in $\mathrm{A}$ and $\mathrm{C}$, respectively. Phage particles adsorbed on a bacterial cell are denoted in B and D (dashed bracket). Phage particles inside a bacterial cell are denoted in D (arrowhead). $\mathrm{SE}=$ sieve element $\mathrm{CC}=$ companion cell. 
the presence of form I), nested PCR using primer sets E and $\mathrm{E}+$ and $\mathrm{C}$ and $\mathrm{C}+$ products yielded stronger bands from the same DNA samples. Form IV was found in all hosts. The fact that primer sets $\mathrm{E}+$ and $\mathrm{C}+$ found in forms I or IV yielded stronger bands than primer set $\mathrm{A}+$ found in forms $\mathrm{I}$ and $\mathrm{V}$ in psyllid alimentary canals rather than equivalent bands is presumptive evidence for the existence of form IV, as well as form I, in psyllid alimentary canals. By extension, form IV was also presumed present in both citrus and periwinkle, although this deduction could not be established by the methods used.

The unique primers of set $\mathrm{F}(04952 \mathrm{~F}$ and $33575 \mathrm{~F})$, together with the unique nested primers of set $\mathrm{F}+(04952 \mathrm{~F} 1$ and $33575 \mathrm{RS}$ ), readily identified and confirmed, respectively, the existence of form III in ' $\mathrm{Ca}$. L. asiaticus' plant hosts, with both prophage simultaneously and completely excised from the chromosome; form III was not detected in psyllid alimentary canals. Both forms II and III were difficult to detect and were found only in planta (and in whole psyllids but not in psyllid alimentary canals). Existence of form II was demonstrated by amplification of PCR products using primer sets D and I followed by nested primer sets D+ and I+.
Highly variable prophage integration junction region found among recent Florida ' $\boldsymbol{C} \boldsymbol{a}$. L. asiaticus' samples.

Nested primer set 375-P2 and 33575RS (Figs.1B and 3) were used to amplify, clone, and sequence the prophage integration junction region (from positions 6,410 to 8,496 on psy62 (NC_012985.2) from three different Florida ' $C a$. L. asiaticus' samples: UF506 (originally isolated from Delray Beach, FL, U.S.A.), a ' $C a$. L. asiaticus' sample from Sebring, FL, U.S.A., obtained from the Florida Division of Plant Industry (DPI), and a ' $C a$. L. asiaticus' sample from infected whole psyllids (and psyllid alimentary canals) raised on ' $\mathrm{Ca}$. L. asiaticus'infected citrus budwood from multiple south Florida sources at the Citrus Research and Education Center (CREC), University of Florida, (Lake Alfred, FL, U.S.A.) (Supplementary Fig. S4). Three PCR products each were sequenced from two separate samples from UF506 and from CREC-raised psyllids and from one DPI sample. In all cases, the three sequenced regions from any one sample were identical. Both UF506 samples were identical but differed in sequence from all other samples $(50$ mismatches out of 2,088 bp with psy62). The two psyllid samples differed among themselves (two mismatches) and all other samples (44 mismatches with psy62). The DPI sample

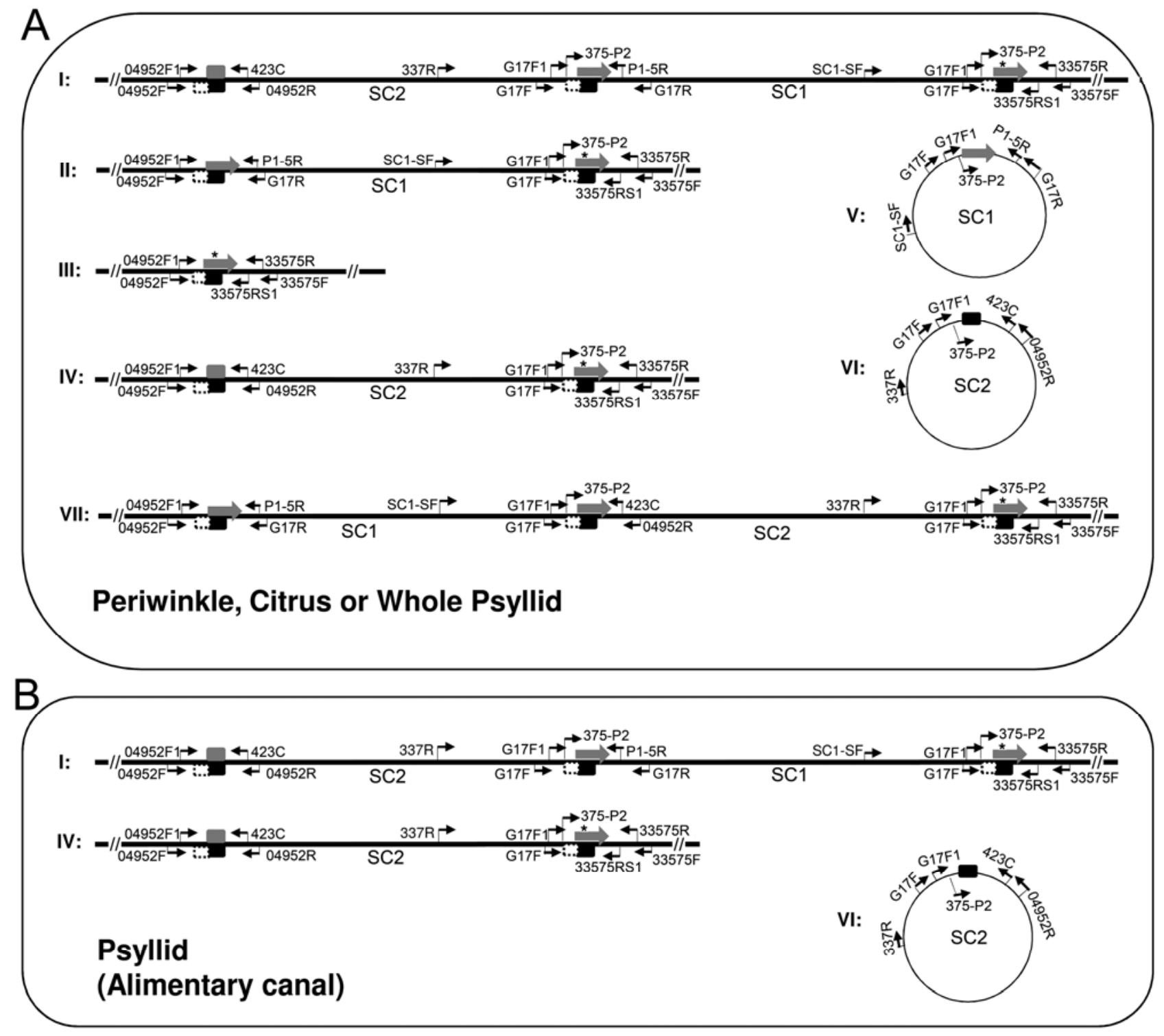

Fig. 3. Illustration of all $\mathrm{SC} 1$ and $\mathrm{SC} 2$ forms found. A, Phage forms found in periwinkle, citrus, and whole psyllids. B, Phage forms found in psyllid alimentary canals. Primers used to determine the integration sites and the presence or absence of the various forms are shown. 
differed from all other samples (but had only two mismatches with psy62).

\section{Annotation of predicted ORF and replication origins of SC1 and SC2.}

SC1 and SC2 had an average \%GC content of 41.2 and $39.4 \%$, respectively, both of which are slightly higher than the average $36 \% \mathrm{GC}$ content of Florida ' $\mathrm{Ca}$. L. asiaticus' psy62. Both phages appeared similarly organized, with early genes associated with DNA replication generally organized to the right and late genes associated with the lytic cycle, including phage structural genes, to the left (Fig. 4). The gene order of SC1 and SC2 are presented left to right, beginning with UF506 genes contiguous with the sequence of SC2 as it was found in the predominant form I (GenBank accession HQ377374), integrated into the UF506 genome and proceeding through SC1, until ending in the chromosome of UF506 to the right (Fig. 3).

The early-gene coding regions of both phages were $93 \%$ identical in sequence along one or more entire regions. All unique genes were found in the late-gene regions of the phage. Most ORF were called by GeneMark, and all were named as $S C 1 \_g p$ " $X$ " if on SC1 and $S C 2 \_g p$ " $X$ " if on SC2, such that the suffixes are identical if a homolog was found on both phages. For example, both phages encoded $100 \%$ identical predicted primase (SC1_gp165, SC2_gp165), exonucleases (SC1_gp195, SC2_gp195), DNA polymerases (SC1_gp210, SC2_gp210), endonucleases (SC1_gp215, SC2_gp215), helicases (SC1_ gp220, SC2_gp220), and DNA ligases (SC1_gp225, SC2_ gp225). Both phages also contained slightly different major capsid proteins (gp090), major tail subunits (gp085), and phage P22 C2-like helix-turn-helix repressors, which prevent transcription of proteins involved in the lytic cycle (gp125). Both phages also carried two Bro-N family (pfam02498) antirepressor genes each ( $g p 155$ and $g p 200)$; antirepressors are involved in activation of the lytic cycle. Both phages carried both the large and small subunits of phage terminase (gp115 and gp120), the enzyme that cleaves virion-length molecules from concatemeric, rolling-circle replicating DNA (i.e., the circular forms $\mathrm{V}$ and $\mathrm{VI}$ ) at the cos sites, forming the nonintegrated, linear phage DNA observed in the Southern blots.

Both phages encoded two adjacent peroxidases (gp095 and gp100). These genes are likely involved in adaptation of ' $\mathrm{Ca}$. $\mathrm{L}$. asiaticus' (lysogenic conversion) to both psyllids and plants. Phage SC2, which is found as an excision plasmid in ' $C a$. L. asiaticus'-infected psyllids and in planta, carried a unique putative autotransporter adhesin gene (SC2_gp240) and an adjacent, unique, collagen triple-helix-repeat gene ( $\left.S C 2 \_g p 245\right)$, both likely involved in insect acquisition. Homologs of these were not found on SC1. By contrast, phage SC1 encoded potential lysis genes, including a putative inner membrane-penetrating holin $\left(S C 1 \_g p 110\right)$ and a potential endolysin (SC1_gp035). However, these two genes are not adjacent to each other, as is typical, and the similarity of SC1_gp035 to an endolysin (e-value $=0.8$ ) was much lower than a chromosomally encoded, murein lytic enzyme (CLIBASIA_04790; similarity to an endolysin at e-value $=2 \mathrm{e}-27)$, located about 33 $\mathrm{kb}$ away from the prophage region on psy62 (and presumably in UF506). Notably, SC1 carried a putative colicin (SC1_gp060)
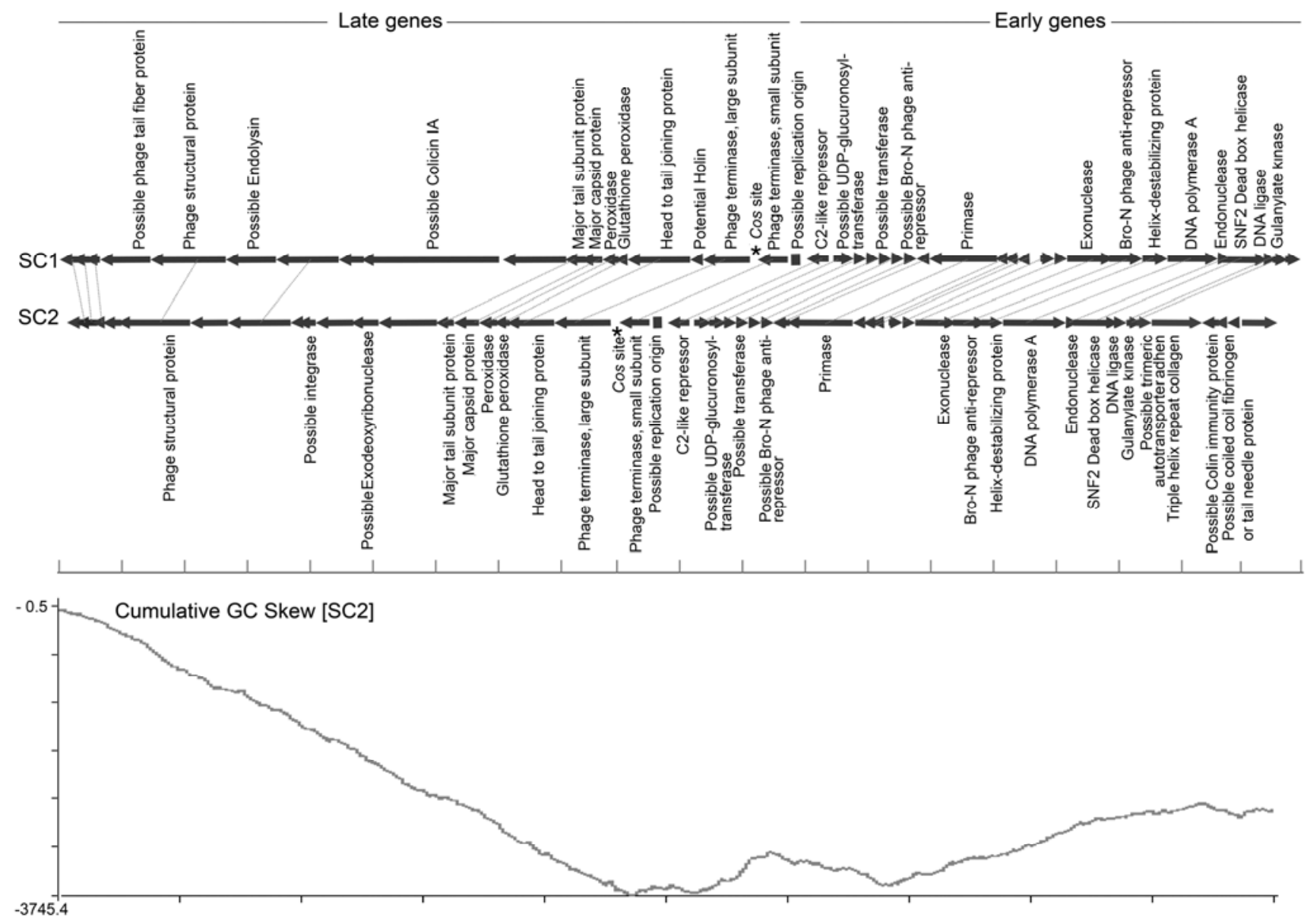

Fig. 4. Alignment of SC1 (GenBank accession HQ377372) with SC2 (GenBank accession HQ377373) and brief annotation. Genes with similar protein sequences are linked by dotted lines. Asterisks indicate the experimentally determined cos region of each phage; rectangles indicate likely phage/plasmid origins of replication. 
encoded among the late SC1 genes, while SC2 carried a putative cognate colicin immunity protein (SC2_gp255) encoded among the early SC2 genes, thus ensuring survival of bacterial cells carrying SC2 but not SC1. Interestingly in this context, a putative phage integrase was found on SC2 (gp065) but not $\mathrm{SC} 1$, thus ensuring that the order of integration must be $\mathrm{SC} 2$ followed by or simultaneously with $\mathrm{SC}$; integrases catalyze unidirectional recombination between a phage site and a bacterial chromosomal site. Another phage integrase is annotated in psy62 (Clibasia_00065) and was also found in UF506 (UF506_050), which is located $2.3 \mathrm{~kb}$ downstream of SC1 on the UF506 chromosome.

The replication origins of SC1 and SC2 were predicted to be located in an intergenic region between genes gp120 and gp125 (positions shown in Figures 1A and 4) by cumulative GC skew analysis (Lobry 1996). The lowest point in the plot indicates the origin of replication (Grigoriev 1998; Tang et al. 2002). In both SC1 and SC2, the low point coincided with the largest intergenic region on each phage and also coincided with many direct and inverted repeats (data not shown). In addition to cumulative GC skew minima, both latter features are generally characteristic of replication origins of both plasmids and phage (Chattoraj 2000; Soler et al. 2010). SC2, which replicated as a prophage plasmid, carried almost twice the number of inverted repeats as SC1 in this region.

\section{DISCUSSION}

Despite numerous electron micrographs of ' $\mathrm{Ca}$. L. asiaticus'infected citrus published over many years in several countries (D. K. Chen et al. 1971; M. H. Chen et al. 1979; Igwegbe and Calavan 1970; Laflèche and Bové. 1970a and b; Tanaka et al. 2004), phage have not previously been reported in association with HLB disease or with any ' $\mathrm{Ca}$. Liberibacter' species. A single prophage region was identified in ' $\mathrm{Ca}$. L. asiaticus' psy62, but neither circular phage genomes nor the presence of a second prophage were suspected or found (Duan et al. 2009). In that study, psyllids were used as a source of ' $\mathrm{Ca}$. L. asiaticus' DNA. By contrast, the approach taken here was to utilize infected dodder from infected periwinkles as the source of ' $\mathrm{Ca}$. L. asiaticus' DNA, resulting in a set of contigs that were surprisingly phage-biased. As it turned out, the bias was due to lytic cycle activation of two prophage and subsequent phage particle formation in ' $\mathrm{Ca}$. L. asiaticus'-infected periwinkles. Samples of ' $\mathrm{Ca}$. L. asiaticus' taken from the alimentary canals of infected psyllids carried only prophage forms and SC2 as plasmid. No evidence indicated lytic cycle activation in psyllids. Southern blots of ' $\mathrm{Ca}$. L. asiaticus'-infected periwinkle revealed that linear forms of both $\mathrm{SC} 1$ and $\mathrm{SC} 2$ cut at cos sites predominated in periwinkle. Relative quantification of phage genes by rtPCR revealed consistently high levels of phage genes in ' $\mathrm{Ca}$. L. asiaticus'-infected periwinkle and inconsistent levels in citrus, although still higher than those found in whole psyllids. In double-blind experiments, phage particles were evident in nine out of 10 samples of ' $\mathrm{Ca}$. L. asiaticus'-infected periwinkles and were not found in 10 samples of uninfected periwinkle. Free phage particles and phage particles infecting ' $\mathrm{Ca}$. L. asiaticus' cells were found only in phloem cells (Fig. 2). The fact that phage have not previously been reported in association with HLB may be attributed to the fact that SC1 and SC2 only reliably enter the lytic cycle, in which they might be detected, in periwinkle and not in citrus and remain as stable lysogens in psyllids.

The use of DNA extracted from dodder rather than periwinkle or citrus reduced but did not eliminate contaminating chloroplast DNA in the plant samples (data not shown). The direct use of citrus from field samples was by far the worst source of ' $\mathrm{Ca}$. L. asiaticus' DNA for MDA and subsequent sequencing since, in addition to contaminating chloroplast and mitochondrial DNA, this approach also isolated DNA of multiple bacterial species as well as ' $\mathrm{Ca}$. L. asiaticus' (data not shown). Surface-sterilized citrus typically shows high numbers of culturable endophytic bacteria of multiple bacterial species, ranging from $10^{3}$ to $10^{4} \mathrm{CFU} / \mathrm{g}$ fresh weight of tissue (Araujo et al. 2002).

In keeping with size estimates of MDA products ranging from 2 to $>100 \mathrm{~kb}$ (Lasken 2005), the UF506 MDA product from ' $\mathrm{Ca}$. L. asiaticus'-infected dodder was large enough to create a fosmid library with inserts $>30 \mathrm{~kb}$ in size. Two highly related, circular phage genomes readily assembled from a combination of the fosmid DNA sequences together with contigs from shotgun sequencing of the same MDA product. This resulted in assembly of two, highly related, circular contigs (Fig. 1A) of 40,048 and 38,997 bp, named SC1 (Fig. 3, form V) and SC2 (Fig. 3, form VI). Southern blots revealed that these circular forms of phage-from ' $\mathrm{Ca}$. L. asiaticus'-infected dodder attached to ' $\mathrm{Ca}$. L. asiaticus'-infected periwinkleswere not the predominant forms of phage found in ' $\mathrm{Ca}$. L. asiaticus'-infected periwinkles, however. The predominant forms found in ' $\mathrm{Ca}$. L. asiaticus'-infected periwinkles were linear, full-length DNAs of each phage, broken by presumed cos sites, indicating that this DNA was extracted from mature phage particles. Phage cos sites are short DNA regions on double-stranded phage that are i) required for phage packaging and infectious phage particle formation, ii) recognized and cleaved by the phage terminase acting as a site-specific endonuclease, and iii) packaged into the phage head or capsid protein, also guided by the phage terminase (Calendar 2006). Hence, one of the restriction endonuclease fragments predicted from the circular phage genome (Fig. 1) will form two smaller fragments than the one predicted if it carries a cos site that has been cut by a terminase. For example, one of the predicted Bam HI restriction fragments of SC1, a 14.4-kb fragment that should hybridize with the SC1-specific probe 2 , in fact, hybridized to a 5.1-kb fragment in Southern blots of DNA extracted from ' $\mathrm{Ca}$. L. asiaticus'-infected periwinkle.

Phage taxonomy is currently based on both morphology (Ackermann 1998) and comparative genomics of the structural genes, particularly the head cluster (Proux et al. 2002). Based on the estimated, relatively short, tail length, apparent head shape, and also the nearest match to the nr database of the structural genes, including the T7-like major capsid proteins, SC1 and SC2 should be classified in family Podoviridae in the order Caudovirales.

Although the presence of a tail on one or both SC1 and SC2 phages was not directly visualized by the staining techniques used in this study, both phages were found to encode proteins with high similarity to annotated major phage tail proteins. $\mathrm{SC} 1$ encodes a predicted protein (gp025) with seven continuous perfect tandem repeats of EMAVLTQKMNIIDGIVNNLA TQTKDVGR and 21 perfect tandem repeats of KLEQIDLS. Phage tail fiber proteins and tape measure proteins adopt extended, fibrous conformations, and they often contain repeats that reflect these structures. These repeats are sometimes found to match other 'unrelated' extended proteins, such as myosin and collagen, as well as long coiled-coil proteins. SC2 also possesses a gene encoding a protein unique to $\mathrm{SC} 2$ with a collagen-like, triple-helix-repeat collagen-like repeat ( $g$ 245). It contains a $\mathrm{NH}_{2}$-terminal domain of 73 amino acids, followed by a collagen-like region, which includes 42 GPQ, 18 GQT, 18 GQD, and five GPK amino acid repeats. Some phage tail fibers contain substantial numbers of the collagen Gly-X-Y repeat (Smith et al. 1998). However, SC2_gp245 appears to be more related to an adhesin, since it is unique to $\mathrm{SC} 2$ and is po- 
sitioned adjacent to $S C 2 \_g p 240$, with high similarity putative trimeric autotransporter adhesin.

Phages escape from bacterial host cells as part of the lytic cycle, either by extrusion, as with filamentous phages, or by host cell lysis. Host cell lysis requires two events from within, namely, the ability to penetrate the inner membrane of bacteria and the ability to depolymerize the cell wall or murein layer by the action of endolysins. Penetration of the inner membrane is accomplished in many phages by use of small membrane-localized, nonlinear proteins called holins that appear to accumulate in the bacterial inner membrane until reaching a specific concentration, at which time they are thought to selfassemble to permeabilize the inner membrane, and allowing accumulated endolysins access to the murein layer (Grundling et al. 2001; Wang et al. 2003; Young et al. 2000). Holins thus control the timing of lysis. Holins are encoded by genes in at least 35 different families, having at least three topological classes (classes I, II, and III, with three, two, and one transmembrane domains, respectively), all with no detected orthologous relationships (Grundling et al. 2001). A putative holin was identified in SC1 (gp110), having a single transmembrane domain.

There are at least three functionally distinct classes of endolysins: i) glucosaminidases (lysozymes) that attack the glycosidic linkages between the amino sugars of the peptidoglycan, ii) amidases that attack the $N$-acetylmuramoyl-L-alanine amide linkage between the glycan strand and the cross-linking peptide, and iii) endopeptidases that attack the interpeptide bridge linkages (Sheehan et al. 1997). Endolysins are synthesized without an export signal sequence that would permit them immediate access to the peptidoglycan (murein) layer, and they, therefore, usually accumulate in the cytoplasm of phageinfected bacteria until they are released by the activity of holins (Young and Blasi 1995). One gene on SC1 encoded a protein with weak similarity to a potential endolysin (SC1_gp035); interestingly, a chromosomally encoded, murein lytic enzyme (CLIBASIA_04790) with excellent hits against known phage endolysin is annotated in psy62. This putative endolysin gene is not found on either $\mathrm{SC} 1$ or SC2, is well outside the prophage region (approximately $33 \mathrm{~kb}$ away) of psy62, and is assumed to be carried by UF506. It is possible that SC1 and SC2 transcriptionally activate and utilize a chromosomally encoded endolysin, which accumulates until released by a holin from SC1. Alternatively, it is possible that SC1_gp035 or another SC1 or SC2 gene encodes the needed endolysin. It is also possible that the holin is chromosomally encoded and activated simultaneously with the prophage late genes. Further work is required to functionally annotate the active endolysin and holin genes.

Phages that encode virulence factors that are important for pathogenicity can be responsible for the conversion of their hosts from nonpathogenic to pathogenic or a given pathogenic strain to one with increased virulence (Boyd and Brüssow 2002). Two likely lysogenic conversion genes encode the two predicted peroxidases (gp095 and gp100) annotated on both SC1 and SC2. SC2 is found in circular, plasmid form in periwinkle, citrus, and psyllids, which would amplify the copy number of any such genes. The generation of ROS, including superoxide radicals, hydrogen peroxide, and hydroxyl radicals, is among the first lines of defense used by insects (Ha et al. 2005; Hoffmann 2003; 2007) and plants (Torres et al. 2006) against invading microbes. ROS production is significantly upregulated in Wolbachia-infected mosquito cells compared with noninfected cells (Brennan et al. 2008). Wolbachia are obligate, intracellular, $\alpha$-proteobacteria, which commonly infect arthropods and are closely related phylogenetically to ' $\mathrm{Ca}$. L. asiaticus' (Duan et al. 2009). Additional potential lysogenic conversion genes are two predicted adhesins, SC2_gp240 and $S C 2 \_g p 245$. These SC2-unique genes may be useful in attachment to insect vectors (Linke et al. 2006), which may explain the need to possess extra copies expressed from an extra chromosomal replicon.

Finally, a potential colicin IA (SC1_gp060) and potential cognate colicin immunity protein (SC2_gp255) were identified on SC1 and SC2, respectively. Colicins are antibacterial proteins that specifically bind the TonA receptor of related bacteria and enter through the outer membrane pore formed by TolC and kill any competitors lacking the colicin immunity protein. Colicins require a functional type I secretion system, which is present in 'Ca. L. asiaticus' (Duan et al. 2009). The fact that the SC2 replicon carries a putative immunity protein would render ' $C a$. L. asiaticus' cells with SC2 resistant to any colicins produced by $\mathrm{SC} 1$ and also would prioritize SC2 preservation in a given 'Ca. L. asiaticus' strain. Assuming packaging (based on Southern blots and rtPCR evidence) and infectious capability of both phages, SC2 might infect a Liberibacter strain and confer a selective advantage by virtue of its lysogenic conversion genes (conferring major pathogenic advantages), while SC1, by itself, is predicted to be lethal to any strain it can infect (unless it was previously or simultaneously infected with SC2). The hypothesized lethality of SC1 would confer a selective advantage to strains that shed infectious $\mathrm{SC} 1$ particles by virtue of its colicin gene alone, which could eliminate potential competition by similar bacteria in the phloem cell or in the psyllid alimentary canal. This mechanism might also ensure essentially monoculture infections of citrus by only a single ' $\mathrm{Ca}$. $\mathrm{L}$. asiaticus' strain (with SC1 and SC2) at a given time. Over time in a grove setting, this could lead to survival of only the fittest of multiple Liberibacter strains in a case of competition by two or more populations. Intriguingly, in Brazil, ' $\mathrm{Ca}$. L. americanus' used to be the predominant form of Liberibacter causing HLB (Teixeira et al. 2005), but it has been replaced by ' $\mathrm{Ca}$. L. asiaticus' as the predominant species. It is possible that the ' $\mathrm{Ca}$. L. asiaticus' colicin kills ' $\mathrm{Ca}$. L. americanus'. Although ' $\mathrm{Ca}$. L. americanus' is more heat sensitive than ' $\mathrm{Ca}$. L. asiaticus', ' $\mathrm{Ca}$. L. americanus' is now difficult to find even in cooler citrus growing regions of Brazil (Lopes et al., 2009a). Further investigation of Liberibacter colicins seems warranted as a potential control strategy for Liberibacters generally.

Some citrus varieties show much stronger ' $\mathrm{Ca}$. L. asiaticus' disease symptoms than others, even when infected with the same nominal ' $\mathrm{Ca}$. L. asiaticus' strain, and some varieties appear to support higher ' $C a$. L. asiaticus' populations than others, independently of symptoms (Folimonova et al. 2009). We hypothesize that quantitative differences in plant defense responses may account for some of the observed varietal differences in symptoms as well as ' $\mathrm{Ca}$. L. asiaticus' populations, mediated by way of the normal mechanism for phage lytic cycle induction. Lytic cycle activation is typically provoked by environmental factors that cause DNA damage to the bacterial cell, such as peroxides or antibiotics, provoking the SOS stress response (Echols 1986; Wdgrzyn and Wdgrzyn 2005). In the present study, some citrus samples showed high levels of lytic cycle induction (SC1 activation) and some did not, while in infected periwinkle, lytic cycle induction was quite strong and phage particles were reliably formed in nearly all samples taken. This indicates a lack of adaptation of ' $\mathrm{Ca}$. L. asiaticus' to life inside of citrus and (particularly) periwinkle cells, which may be due to induction of plant defense responses, most notably either ROS or phytoalexin generation, or both, that may trigger the ' $\mathrm{Ca}$. L. asiaticus' SOS response. Although phage particles were not observed in citrus and have not been observed by others, it is likely that lysis of ' $\mathrm{Ca}$. L. asiaticus' occurs, at least in some citrus cells. Lytic burst of a relatively large 
bacterial cell inside a living phloem cell (Fig. 2) would likely trigger a cell death or apoptosis cascade, resulting in the subsequent death of the citrus phloem cell. The observed HLB symptom of prominent thickening of leaf veins may be a result of living phloem cells circumventing the dead phloem cells in order to preserve a living phloem connection to distal parts of the vein.

\section{MATERIALS AND METHODS}

\section{UF506 isolation.}

Several young, field-grown citrus trees (Delray Beach, FL, U.S.A.) showing symptoms of HLB but not confirmed positive for ' $\mathrm{Ca}$. L. asiaticus' were removed from the field by the Florida Department of Agriculture and Consumer Services DPI and were transferred under permit to the University of Florida Plant Containment Facility in May 2006. The Florida Department of Agriculture subsequently confirmed by PCR that one of these citrus trees, a grapefruit (Citrus paradisi), was strongly positive for ' $\mathrm{Ca}$. L. asiaticus'. This plant was continuously maintained and used for dodder transmission of ' $\mathrm{Ca}$. L. asiaticus' to periwinkle and citrus trees. Confirmation of the ' $\mathrm{Ca}$. L. asiaticus' diagnosis in citrus was by PCR, using primers OI1 and OI2c (Jagoueix et al. 1996) as the first set and primers CGO3F and CGO5R (Zhou et al. 2007) as the second set, followed by DNA sequencing.

\section{Purification of UF506}

through a periwinkle "filter" and curation.

Transmission of UF506 from citrus to periwinkles (Catharanthus roseus) was via dodder (Cuscuta pentagona). Clean dodder grown from seed that tested negative for ' $\mathrm{Ca}$. L. asiaticus' was applied to the newly infected periwinkles and was used for DNA extractions and to transmit greening symptoms to fresh periwinkles (grown from seed) and also to citrus ( $\mathrm{Cit}$ rus sinensis). 'Ca. L. asiaticus'-infected periwinkles were thus used as a filter to enrich for ' $\mathrm{Ca}$. L. asiaticus', because periwinkles were found to carry fewer contaminating bacteria than citrus. The citrus trees and periwinkle plants infected in this manner were presumed to carry a single ' $\mathrm{Ca}$. L. asiaticus' strain named UF506.

\section{DNA preparation from dodder, MDA, and sequencing.}

Dodder was used for the DNA extraction because dodder was found to have reduced chloroplast content compared with periwinkle and citrus. Primers OI1 and OI2c, standard chloroplast primers trnD-trnT, and standard mitochondrial primers nad1B-nad1C (Demesure et al. 1995) were used to approximate ' $C a$. L. asiaticus', chloroplast, and mitochondria levels. Total DNA was extracted from dodder that carried ' $\mathrm{Ca}$. L. asiaticus' UF506, following attachment to infected periwinkles as described above. Yields of this DNA were low, necessitating use of MDA using REPLI-g (Qiagen, Valencia, CA, U.S.A.) to obtain sufficient DNA for shotgun library sequencing and cloning. DNA sequencing and machine assembly into contigs was performed by SeqWright (Houston, TX, U.S.A.). BLAST and PFAM analyses were performed by the University of Florida's Interdisciplinary Center for Biotechnology Research (ICBR) Genomics Core Facility.

\section{Validation of contigs.}

The largest 100 contigs, ranging in size from 1.2 to $17 \mathrm{~kb}$, were analyzed by comparisons against the GenBank nr database using BLAST and PFAM. Those that appeared to be plant nuclear DNA, chloroplast, mitochondrial, or bacterial DNA with $>50 \%$ GC content were eliminated from further consideration. PCR primers were designed against the remaining contigs using Primer 3.0.4.0 (Rozen and Shaletsky 2000); these primers typically amplified an approximately 200-bp product by default. Validation of contig regions by PCR was always performed on four independent samples per contig region: one from ' $\mathrm{Ca}$. L. asiaticus'-infected citrus, one from ' $\mathrm{Ca}$. L. asiaticus'-infected periwinkle, one from uninfected citrus, and one from uninfected periwinkle. Validation of a contig region was considered confirmed only if both ' $\mathrm{Ca}$. L. asiaticus'infected samples were positive and both uninfected samples were negative. Additional primers were subsequently designed in different regions of larger contigs, and large PCR products were obtained to confirm larger assemblies.

\section{Fosmid library construction, clone identification, and fosmid walking.}

The majority of the UF506 MDA product was $>30 \mathrm{~kb}$ in size (discussed above) and, therefore, was large enough to create a fosmid library. Following MDA, the DNA was size fractionated using a 10 to $40 \%$ sucrose gradient, and fractions $>30 \mathrm{~kb}$ were precipitated and blunt end polished, were ligated into CopyControl pCC2FOS vector (Epicentre, Madison, WI, U.S.A.), and were transfected into Escherichia coli. Following growth, 1,400 colonies were individually plated and replicated onto nylon membranes and were also transferred into glycerolized stocks in a 96-well microtiter plate format. Putative ' $\mathrm{Ca}$. L. asiaticus-specific DNA probes were identified by sequencing and metagenomic analysis, were created by PCR, and were confirmed ' $C a$. L. asiaticus'-specific by PCR. Confirmed ' $C a$. L. asiaticus'-specific DNA probes were cloned into pGEM-T and were then labeled with ${ }^{32} \mathrm{P}$ for Southern blot hybridizations. Fosmids identified as ' $\mathrm{Ca}$. L. asiaticus'-specific were first sequenced from vector-based primers, followed by subsequent sequencing of the entire fosmid by primer walking. All fosmids were sequenced in both directions. Fosmid DNA was sequenced by the University of Florida ICBR Genomic DNA Core Facility.

\section{Southern blot hybridizations.}

Total DNA was extracted from ' $\mathrm{Ca}$. L. asiaticus'-infected periwinkle and from uninfected periwinkle leaves using a Qiagen DNeasy plant maxi kit (Qiagen). Periwinkle DNA samples were digested with appropriate enzymes, and $15 \mu \mathrm{g}$ of DNA was loaded per lane. Southern blots were as described (Sambrook and Russell 2000).

\section{DNA extractions for comparative purposes and quantitative reverse transcription PCR.}

Total DNA from symptomatic greenhouse citrus and periwinkle plants was extracted from $100 \mathrm{mg}$ of homogenized midribs using the DNeasy plant mini kit (Qiagen), as suggested by the manufacturer.

Total DNA from whole Diaphorina citri that had been reared on citrus plants infected with HLB was extracted as follows. Adult whole psyllids (15 to 20) were placed on ice to immobilize them, were washed twice with $70 \% \mathrm{ETOH}$, were washed 20 times with sterile deionized water, and were rinsed once with, and finally resuspended in, $400 \mu$ of BBM buffer (with 1 liter of BBM buffer consisting of $6 \mathrm{~g}$ of brain heart infusion [BBL, Baltimore, MD, U.S.A.], $10 \mathrm{~g}$ of $\mathrm{N}$-(2acetamido)-2-aminoethanesulfonic acid, $3.76 \mathrm{~g}$ of $\mathrm{KOH}$, and $20 \mathrm{~g}$ of mannitol, [pH 6.9]). The psyllids were then homogenized with a small plastic pestle in a $1.5-\mathrm{ml}$ microcentrifuge tube. The suspension was clarified by filtration at $8,000 \mathrm{rpm}$ for $10 \mathrm{~min}$, using a $5.0-\mu \mathrm{m}$ polyvinylidene difluoride centrifugal filter (Millipore Corp., Billerica, MA, U.S.A.), and the resulting pellet was then resuspended in $100 \mu \mathrm{l}$ of BBM buffer. DNA was extracted from the suspension using a Wizard Ge- 
nomic DNA purification kit (Promega Corporation, Madison, WI, U.S.A.), following the manufacturer's instructions.

For DNA extractions from psyllid alimentary canals, individual psyllids were placed in a 50- $\mu$ l drop of buffer and were teased apart with fine forceps. The alimentary canals were then removed and were subjected to the same DNA extraction procedure as used with whole psyllids.

In all cases, conventional PCR was performed with ' $\mathrm{Ca}$. L. asiaticus' primers OI1 and OI2c (Jagoueix et al. 1996) to confirm ' $C a$. L. asiaticus' infection. ' $C a$. L. asiaticus' quantification was based on standard curves with the ' $\mathrm{Ca}$. L. asiaticus' gene prfA cloned in pGEM-T, as previously described ( $\mathrm{Li}$ et al. 2009), and adjusted to 100 copies of prfA per sample. Relative fold abundance of phage target genes was determined by using the change in cycle threshold method (Bio-Rad Laboratories. Hercules, CA, U.S.A.), using the ' $\mathrm{Ca}$. L. asiaticus' prfA (CLIBASIA_03855) gene as the reference.

\section{TEM, phage particle identification, and size estimation.}

TEM was performed on 20 similar periwinkle samples from the University of Florida Plant Containment Facility in a double-blind experiment. UF506-infected periwinkles and healthy periwinkles (10 of each) from a different greenhouse and not exposed to ' $\mathrm{Ca}$. L. asiaticus' were selected. Prior to the experiment, confirmation that the 10 UF506-infected periwinkles were ' $\mathrm{Ca}$. L. asiaticus'-positive and confirmation that the 10 healthy periwinkles were ' $C a$. L. asiaticus'-negative was obtained by nested PCR using primers OI1 and OI2c (Jagoueix et al. 1996) as the first set and primers CGO3F and CGO5R (Zhou et al. 2007) as the second set. The 20 samples were then assigned codes and presented to the ICBR Electron Microscopy Facility, which performed the TEM work without prior knowledge of coding or the number of ' $\mathrm{Ca}$. L. asiaticus'-positive and 'Ca. L. asiaticus'-negative samples.

Periwinkle leaf samples were fixed in $4 \%$ paraformaldehyde plus $2 \%$ glutaraldehyde in $0.1 \mathrm{M}$ sodium cacodylate $(\mathrm{pH} 7.24)$. The fixed tissue samples were then washed in $0.1 \mathrm{M}$ sodium cacodylate buffer followed by $1 \%$ tannic acid. Post fixation was carried out with $2 \% \mathrm{OsO}_{4}$. After thoroughly removing $\mathrm{OsO}_{4}$ by rinsing them with water, the samples were dehydrated in a graded ethanol series, followed by $100 \%$ acetone. Dehydrated samples were infiltrated in graded acetone/Spurrs epoxy resin and were cured at $60^{\circ} \mathrm{C}$ (Ellis 2006). The tissue processing was performed with the aid of a Pelco BioWave laboratory microwave (T. Pella, Redding, CA, U.S.A.). Cured resin blocks were trimmed, thin-sectioned (80 to $100 \mathrm{~nm}$ thick), and collected on Formvar-coated copper slot grids. The sections were poststained with $2 \%$ aqueous uranyl acetate and Reynold's lead citrate and were examined with a Hitachi H-7000 TEM (Hitachi High Technologies America, Schaumburg, IL, U.S.A.), operated at $100 \mathrm{kV}$. Electron micrographs were acquired with a Veleta camera $(2 \mathrm{~K} \times 2 \mathrm{~K})$ controlled by the iTEM software package (Olympus Soft-Imaging Solution, Lakewood, CO, U.S.A.). Results were recorded as bacteria present or not in phloem cells and phage present or not in phloem cells in each of 20 samples. Results were decoded and correlated with the PCR results.

The average phage head size was based upon measured diameters of 57 phage particles, and the average phage neck length was calculated from 25 phage particles adsorbed on the bacterial cell surface. Head size diameters and neck lengths were measured with the Image J software package $(1.38 \times, \mathrm{Na}-$ tional Institute of Health ImageJ website).

\section{Phage genome assembly, ORF prediction, and bioinformatic analysis.}

Fosmid DNA sequences were assembled, together with contigs produced by direct 454 sequencing using ContigExpress, and some comparisons were made using AlignX (Invitrogen, Carlsbad, CA, U.S.A.). Protein coding regions were predicted using GeneMark (Besemer and Borodovsky 1999). Gene annotation was performed by hand using BlastP and $\mathrm{HH}$ pred. $\mathrm{Cu}-$ mulative GC skew plots were made using the University of Pittsburgh Bioinformatics Software and Web Tools Collection GC Skew Tool.

\section{ACKNOWLEDGMENTS}

We thank P. A. Rayside and S. Reddy (Plant Pathology Department, University of Florida, Gainesville) for their excellent technical assistance in ' $\mathrm{Ca}$. L. asiaticus' strain curation and ' $\mathrm{Ca}$. L. asiaticus' plant infections. We thank D. S. Williams (Microbiology and Cell Science Dept, University of Florida) for TEM imaging. This work was supported by the United States Department of Agriculture APHIS award 06-8100-1103 CA and by Florida Citrus Advanced Technology Program award \#65.

\section{LITERATURE CITED}

Ackermann, H. W. 1998. Tailed bacteriophages: The order Caudovirales. Adv.Virus Res. 51:135-201.

Araujo, W. L., Marcon, J., Maccheroni, W., Jr., Van Elsas, J. D., Van Vuurde, J. W., and Azevedo, J. L. 2002. Diversity of endophytic bacterial populations and their interaction with Xylella fastidiosa in citrus plants. Appl. Environ. Microbiol. 68:4906-4914.

Besemer, J., and Borodovsky, M. 1999. Heuristic approach to deriving models for gene finding. Nucleic Acids Res. 27:3911-3920.

Bové, J. M. 2006. Huanglongbing: A destructive, newly-emerging, century-old disease of citrus. J. Plant Pathol. 88:7-37.

Boyd, E. F., Davis, B. M., and Hochhut, B. 2001. Bacteriophage-bacteriophage interactions in the evolution of pathogenic bacteria. Trends Microbiol. 9:137-144.

Boyd, E. F., and Brüssow, H. 2002. Common themes among bacteriophage-encoded virulence factors and diversity among the bacteriophages involved. Trends Microbiol. 10:521-529.

Brennan, L. J., Keddie, B. A., Braig, H. R., and Harris, H. L. 2008. The endosymbiont Wolbachia pipientis induces the expression of host antioxidant proteins in an Aedes albopictus cell line. PLoS One. 3:e2083. Published online.

Brlansky, R. H., and Rogers, M. E. 2007. Citrus Huanglongbing: Understanding the vector-pathogen interaction for disease management. Plant Health Progr. doi: 10.1094/APSnetFeature-2007-1207. Published online.

Calendar, R. 2006. The bacteriophages, 2nd ed., Oxford University Press, New York.

Casjens, S. 2003. Prophages and bacterial genomics: What have we learned so far? Mol. Microbiol. 49:277-300.

Chattoraj, D. K. 2000. Control of plasmid DNA replication by iterons: No longer paradoxical. Mol Microbiol. 37:467-476.

Chen, M. H, Miyakawa, T., and Matsui, C. 1971. Mycoplasmalike bodies associated with likubin-diseased Ponkan citrus. Phytopathology. 61:598.

Chen, T. Y., Shen, C. Y., Tao, S. C., Kung, T. H., Chao, H. Y., Chiang, Y. H., Chiu, C. S. 1979. Mycoplasma-like organisms associated with huanglongping in Kwangxi. Acta Biochimica et Biophysica Sinica. 11:389-391.

Citrus Research Board. 2008. The insect: Asian citrus psyllid. Citrus Research Board, Visalia, CA, U.S.A. Published online.

Coletta-Filho, H. D., Takita, M. A., Targon, M. L. P. N., and Machado, M. A. 2005. Analysis of $16 \mathrm{~S}$ rDNA sequences from citrus Huanglongbing bacteria reveal a different ' $\mathrm{Ca}$. Liberibacter' strain associated with citrus disease in São Paulo. Plant Dis. 89:848-852.

Da Graça, J. V., and Korsten, L. 2004. Citrus Huanglongbing: Review, present status and future strategies. Springer, Amsterdam.

Demesure, B., Sodzi, N., and Petit, R. J. 1995. A set of universal primers for amplification of polymorphic non-coding regions of mitochondrial and chloroplast DNA in plants. Mol. Ecol. 4:129-131.

Duan, Y. P, Gottwald, T., Zhou, L, J., and Gabriel, D. W. 2008. First report of dodder transmission of 'Candidatus Liberibacter asiaticus' to tomato (Lycopersicon esculentum). Plant Disease. 92:831.

Duan, Y. P, Zhou, L., Hall, D. G., Li, W., Doddapaneni, H., Lin, H., Liu, L., Vahling, C. M., Gabriel, D. W., Williams, K. P., Dickerman, A., Sun, Y., and Gottwald, T. 2009. Complete genome sequence of citrus Huanglongbing bacterium, 'Candidatus Liberibacter asiaticus' obtained through metagenomics. Mol. Plant-Microbe Interact. 22:1011-1020.

Echols H. 1986. Bacteriophage development: Temporal switches and the choice of lysis or lysogeny. Trends Genet. 2:26-30.

Ellis, E. A. 2006. Solutions to the problem of substitution of ERL 4221 for 
vinyl cyclohexene dioxide in Spurr low viscosity embedding formulations. Microsc. Today 14:32-33.

Folimonova, S. Y., Robertson, C. J., Garnsey, S. M., Gowda, S., and Dawson, W. O. 2009. Examination of the responses of different genotypes of citrus to Huanglongbing (Citrus Greening) under different conditions. Phytopathology 99:1346-1354.

Garnier, M, and Bové, J. M. 1983. Transmission of organism associated with citrus greening disease from sweet orange to periwinkle by dodder. Phytopathology 73:1358-1363.

Gottwald, T. R., da Graça, J. V and Bassanezi, R. B. 2007. Citrus Huanglongbing: The pathogen and its impact. Plant Health Progr. doi:10.1094/PHP-2007-0906-01-RV. Published online.

Grigoriev, A. 1998. Analyzing genomes with cumulative skew diagrams. Nucleic Acids Res. 26:2286-2290.

Grundling, A., Manson, M. D., and Young, R. 2001. Holins kill without warning. Proc. Natl. Acad. Sci. U.S.A. 98:9348-9352.

Ha, E. M., Oh, C. T., Ryu, J. H., Bae, Y. S., Kang, S. W., Jang, I. H., Brey, P. T., and Lee, W. J. 2005. An antioxidant system required for host protection against gut infection in Drosophila. Dev. Cell. 8:125132.

Halbert, S. E., and Manjunath, K. L. 2004. Asian citrus psyllids (Sternorrhyncha: Psyllidae) and greening disease of citrus: A literature review and assessment of risk in Florida. Fla. Entomol. 87:330-353.

Hansen, A. K., Trumble, J. T., Stouthamer, R., and Paine, T. D. 2008. A new Huanglongbing species, 'Candidatus Liberibacter psyllaurous' found to infect tomato and potato, is vectored by the psyllid Bactericera cockerelli (Sulc). Appl. Environ. Microbiol. 74:5862-5865.

Hoffmann, J. A. 2003 The immune responses of Drosophila. Nature. 426:33-38.

Hoffmann, J. A. 2007. Antifungal defense in drosophila. Nat. Immunol. 8:543-545.

Igwegbe, E. C. K., and Calavan, E. C. 1970. Occurrence of mycoplasmalike bodies in phloem of stubborn-infected citrus seedlings. Phytopathology 60:1525-1526.

Jagoueix, S., Bové, J. M., and Garnier, M. 1996. PCR detection of the two 'Candidatus' Liberobacter species associated with greening disease of citrus. Mol. Cell Probes. 10:43-50.

Jagoueix, S., Bové, J. M., and Garnier, M. 1997. Comparison of the $16 \mathrm{~S} / 23 \mathrm{~S}$ ribosomal intergenic regions of 'Candidatus Liberobacter asiaticum' and 'Candidatus Liberobacter africanum,' the two species associated with citrus huanglongbing (greening) disease. Int. J. Syst. Bacteriol. 47:224-227.

Laflèche D., and Bové, J. M. 1970a. Structures de type mycoplasme dans les feuilles d'orangers atteints de la maladie du greening. Compt. Rend. Acad. Sci. 270:1915-1917.

Laflèche D., and Bové, J. M. 1970b. Mycoplasmes dans les agrumes atteints de 'greening', de 'stubborn' ou de maladies similaires. Fruits. 25:455-465.

Lasken, R. 2005. Multiple displacement amplification of genomic DNA. Pages 99-118 in: Whole Genome Amplification. S. Hughes and R. Lasken, eds. Scion Publishing Ltd. Bloxham, Oxfordshire, U.K.

Li, W., Levy, L., and Hartung, J. S., 2009. Quantitative distribution of 'Candidatus Liberibacter asiaticus' in citrus plants with citrus huanglongbing. Phytopathology. 99:139-144.

Liefting, L. W., Perez-Egusquiza, Z. C., and Clover, G. R. G. 2008. A new 'Candidatus Liberibacter' species in Solanum tuberosum in New Zealand. Plant Dis. 92:1474.

Linke, D., Riess, T., Autenrieth, I. B., Lupas, A., and Kempf, V. A. J. 2006. Trimeric autotransporter adhesins: Variable structure, common function. Trends Microbiol. 14:264-270.

Lobry, J. R. 1996. Asymmetric substitution patterns in the two DNA strands of bacteria. Mol. Biol. Evol. 13:660-665.

Lopes S. A., Bertolini E., Frare G. F., Martins E. C., Wulffm N. A., Teixeiram D. C., Fernandes, N. G., and Cambra, M. 2009a. Graft transmission efficiencies and multiplication of 'Candidatus Liberibacter americanus' and ' $\mathrm{Ca}$. Liberibacter asiaticus' in citrus plants. Phytopathology 99:301-306.

Lopes, S. A., Frare, G. F., Bertolini, E., Cambra, M., Fernandes, N. G., Ayres, A. J., Marin, D. R., and Bové, J. M. 2009b. Liberibacters associated with citrus huanglongbing in Brazil:Candidatus Liberibacter asiati- cus is heat tolerant, $\mathrm{Ca}$. L. americanus is heat sensitive. Plant Dis. 93:257-262.

Proux, C., van Sinderen, D., Suarez, J., Garcia, P., Ladero, V., Fitzgerald, G. F., Desiere, F., and Brussow, H. 2002. The dilemma of phage taxonomy illustrated by comparative genomics of Sfi21-like Siphoviridae in lactic acid bacteria. J. Bacteriol. 184:6026-6036.

Ptashne, M. 2004. A genetic switch: Phage lambda revisited. 3rd ed. Cold Spring Harbor Laboratory Press. New York.

Rozen, S., and Skaletsky, H. 2000. Primer3 on the WWW for general users and for biologist programmers. Methods Mol. Biol. 132:365-386.

Sambrook, J., and Russell, D.W. 2000. Molecular Cloning: A Laboratory Manual. 3rd ed. Cold Spring Harbor Laboratory Press. New York.

Sheehan, M. M., Garcia, J. L., Lopez, R., and Garcia, P. 1997. The lytic enzyme of the pneumococcal phage Dp-1: A chimeric lysin of intergeneric origin. Mol. Microbiol. 25:717-725.

Smith, M. C., Burns, N., Sayers, J. R., Sorrell, J. A., Casjens, S. R., and Hendrix, R. W. 1998. Bacteriophage collagen. Science. 279:1834.

Soler, N., Marguet, E., Cortez, D., Desnoues, N., Keller, J., van Tilbeurgh, H., Sezonov, G., and Forterre, P. 2010. Two novel families of plasmids from hyperthermophilic archaea encoding new families of replication proteins. Nucleic Acids Res. 38:5088-5104.

Sutton, B., Duan, Y. P., Halbert, S., Sun, X.-a., Schubert, T., and Dixon, W 2005. Detection and identification of citrus Huanglongbing (greening) in Florida, U.S.A.. Page 59 in: Proceedings of the Second International Citrus Canker and Huanglongbing Research Workshop, 2005. Orlando, FL, U.S.A.

Tanaka, F. A. O., Kitajima, E. W., de Jesus, W. C., Jr., Ayres, A. J., Gimenes-Fernandes, N. \& Bové, J. M. 2004. First report on electron micrographs of liberibacter-like structures in citrus in Brazil. Page 177: in: Program \& Abstracts of the 16th Conference of the International Organization of Citrus Virologists. Monterrey, Mexico.

Tang, S. L., Nuttall, S., Ngui, K., Fisher, C., Lopez, P., and Dyall-Smith, M. 2002. HF2: A double-stranded DNA tailed haloarchaeal virus with a mosaic genome. Mol. Microbiol. 44:283-296.

Teixeira, D. C., Saillard, C., Eveillard, S., Danet, J. L., da Costa, P. I., Ayres, A. J., and Bové, J. M. 2005. 'Candidatus Liberibacter americanus', associated with citrus huanglongbing (greening disease) in Sao Paulo State, Brazil. Int. J. Syst. Evol. Microbiol. 55:1857-62

Tomimura, K., Miyata, S., Furuya, N., Kubota, K., Okuda, M., Subandiyah, S., Hung, T. H., Su, H. J., and Iwanami, T. 2009. Evaluation of genetic diversity among 'Candidatus Liberibacter asiaticus' isolates collected in Southeast Asia. Phytopathology 99:1062-1069.

Torres, M. A., Jones, J. D., and Dangl, J. L. 2006. Reactive oxygen species signaling in response to pathogens. Plant Physiol. 141:373-378.

Tsai, C. H., Hung, T. H., and Su, H. J. 2008. Strain identification and distribution of citrus Huanglongbing bacteria in Taiwan. Bot. Stud. 49:49-56.

Wagner, P. L., and Waldor, M. K. 2002. Bacteriophage control of bacterial virulence. Infect. Immun. 70:3985-3993.

Wang, I. N., Deaton, J., and Young, R. 2003. Sizing the holin lesion with an endolysin-beta-galactosidase fusion. J. Bacteriol. 185:779-787.

Wdgrzyn G., and Wdgrzyn A. 2005. Genetic switches during bacteriophage lambda development. Prog Nucleic Acid Res Mol Biol. 79:1-48.

Young, I., Wang, I., and Roof, W. D. 2000. Phages will out: Strategies of host cell lysis. Trends Microbiol. 8:120-128.

Young, R., and Blasi, U. 1995. Holins: Form and function in bacteriophage lysis. FEMS (Fed. Eur. Microbiol. Soc.) Microbiol Rev. 17:191-205.

Zhou, L. J., Gabriel, D. W., Duan Y. P., Halbert, S. E., and Dixon, W. N. 2007. First report of dodder transmission of Huanglongbing from naturally infected Murraya paniculata to citrus. Plant Dis. 91:227.

\section{AUTHOR-RECOMMENDED INTERNET RESOURCES}

Genemark wbsite: exon.biology.gatech.edu/heuristic_hmm2.cgi

Max Planck Institute for Developmental Biology HHpred webpage: toolkit.tuebingen.mpg.de/hhpred

The National Center for Biotechnology Information website: http://www.ncbi.nlm.nih.gov

National Institute of Health ImageJ website: rsb.info.nih.gov/ij

GC Skew Tool website: bioinformatics2.pitt.edu/SKEW/index.html 